\title{
أوضاع الكوت السياسية خلال خمسينات القرن العشرين
}

الباهث رائد السوداني

\section{محافظة واسط/العراق}

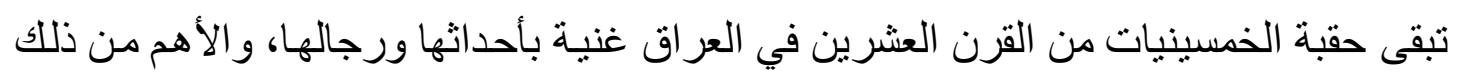

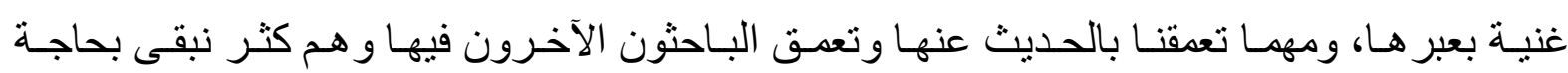

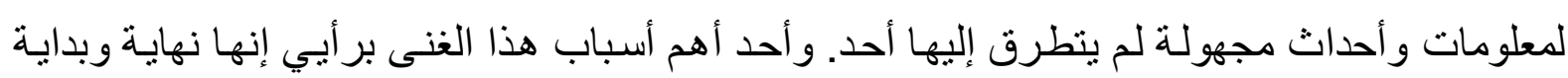

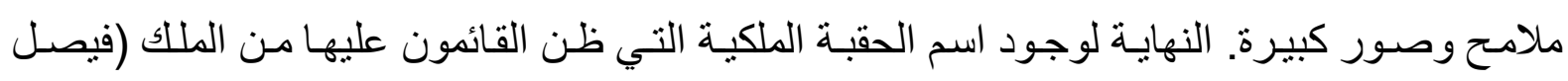

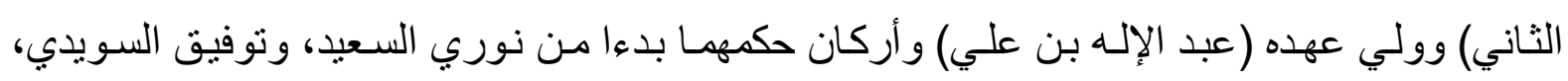

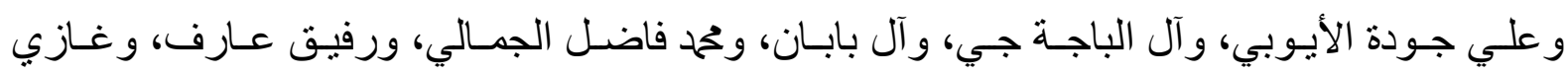

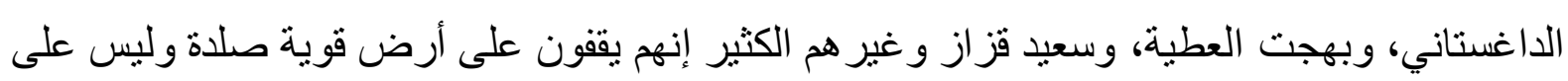

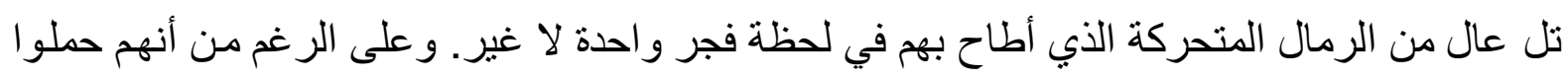

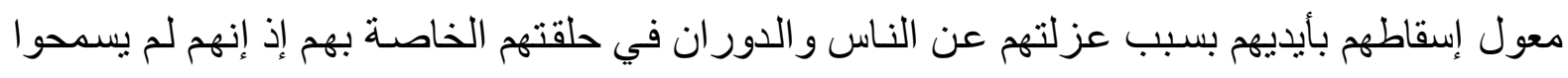

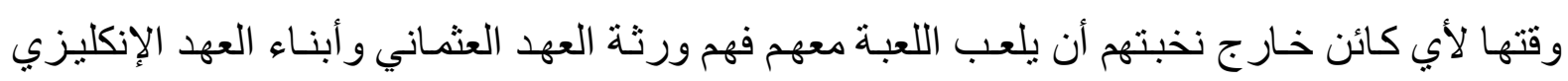

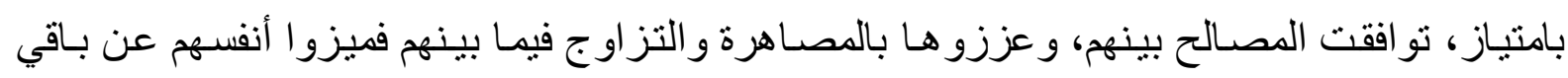

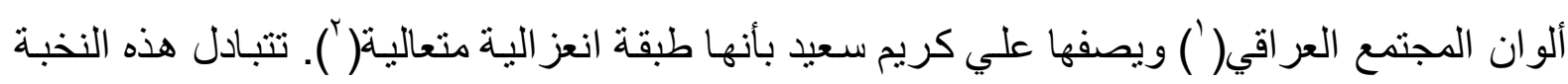

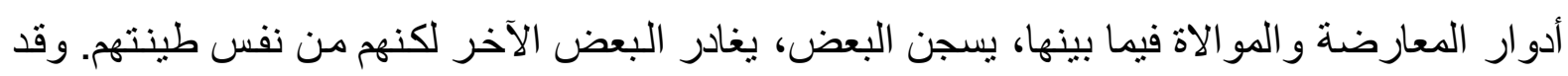

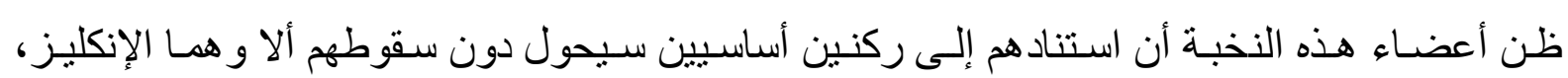
و الإقطاع.

\section{استشراء الإقططاع:}

في حقبة الخمسينيات استشرى الإقطاع بصورة جلية في العر اق لاسيما في الكوت مها كان له

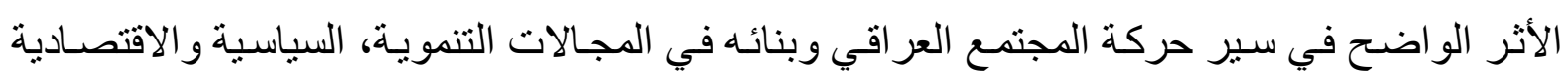

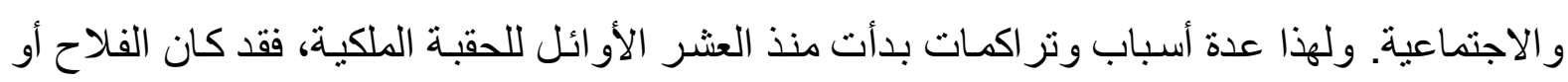

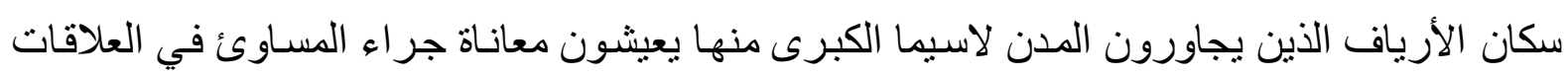

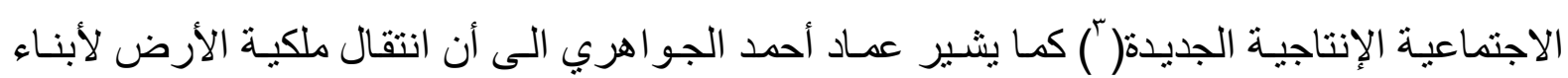

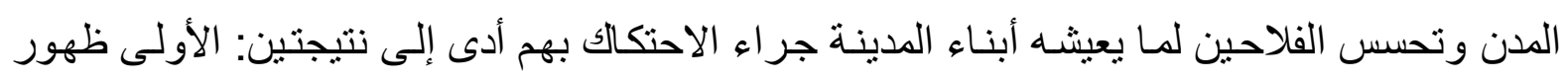

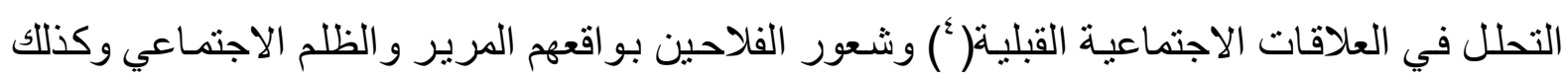

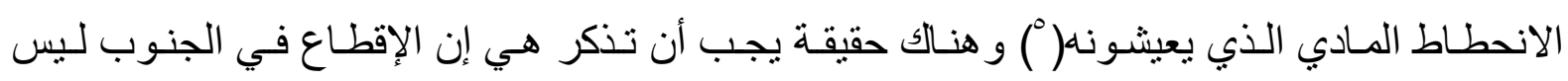

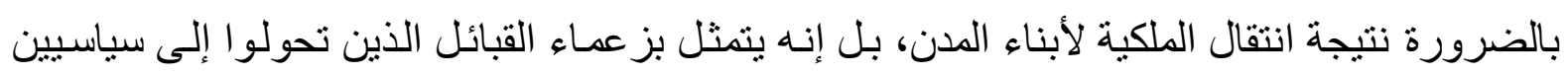


وبرلمانيين و أعضاء مجلس نواب و أعضاء مجلس أعبان، بل حتى وزراء. وبالنتيجة تحولوا إلى سكان مدن يحضـرون إلى مقاطعـاتهم في المناسبات أو عند نهايـة الموسم الزر اعي أو عندما يبغون إظهار

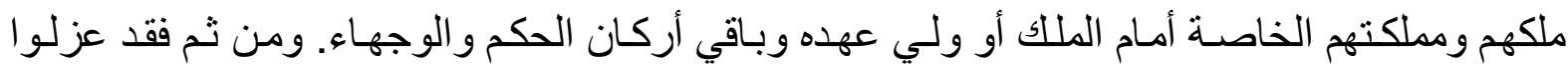
أنفسهم عن أتباعهم ووضعو ا شؤون أر اضيهح و أمو الهم بيد الوكلاء (السر اكيل) القساة ليتفرغو الشؤون السياسة، وبهذا ساهمو ا بحفر حفرة وقعو ا فيها بسر عة دون أن يتداركوا شيئا من مصالحهم عندما وقعت

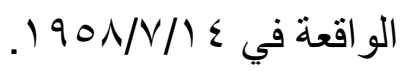

عانى الفلاح كثير ا وتحول في منـاطق الإقطاع إلى كائن بـلا إحساس عند الإقطاعي ووكيله، يُستغل جهده وماله و عياله أبشع استغلال و عليه أن يطيع صاغر ا راضيا و إلا فالعقاب الذي ينتظره شديد ومؤلم. يذكر عماد أحمد الجواهري عن حال الفلاح مـا نصسه "و الواقع فقد كان كل جانب من جوانب حياة الفلاحين بمثابة صرخة إنسانية بائسة تعبر عن مدى الاستغلال العميق الذي يمارس ضد هذه الفئة المحرومة من هذا الثعب، ذلك الاستخلال الذي ساهمت فيه القوى المتسلطة على رقاب الفلاحين ابتداء من الدولة ونهايـة (بأدو ات الثـيخ الآدمية) التي أوجدت لكبح جمـاح الفلاحين"( ). وينقل عمـاد أحمد الجو اهري عن وثيقة رسمية من سكرتير الواردات إلى وزير المالية في جبو (ما يأتي "ولو لم تأخذ الحكومة در اهم الفلاح لسارع الثيخ الجشع أو السركال أو التاجر الذي يعيش بالربح (الربا) إلى تنظيف جيب الفـلاح "( ال). الأمر الذي يؤكد أن الحالة الثـاذة أخذت طريقها مـن وقت مبكر من عمر الحقبـة الملكية.

وقد ذكرنا أن الإقطاع كان أحد ركني الحقبة الملكية، ليس بـالقو انين فقط بـل بالمصـاهرة أيضـا، فأعلى منصب في (الدولة العر اقية) نزوج من كريمة الأمير ححم الحبيب أمبر ربيعة، مما يدل على توحد المصير لدى الجـانبين وكذلك المصـالح المشـتركة بينهما ليس الاقتصـادية فحسب بـل السياسية أيضـا. ويشير حنا بطاطو الى أن ارتباط العائلة المالكة الوثيق مع شيوخ العثـائر صـار رمزا الآن في زواج الأمير عبد الإله من الأميرة هيام كريمة الثيخ تحمد الحبيب أمير ربيعة و هذا انعكاس للعناية الفائقة التي أولتها العائلة المالكة لثبوخ العثـائر في السنوات السبع عشرة الأخيرة( ). ويؤكد بطاطو رأيه حول انعكاس أثز العلاقة بين الطرفين على الحياة الاقتصـادية و الاجتماعية في قوله "وخصوصـا في تكثيف ممارسـة تطبيق قانون تسوية الأر اضـي بمـا فيـه فائدتهم .وبهذه الطريقـة تحولت إلى الملكيـة الخاصـة للمشايخ مساحات واسعة من الأر اضي التي كانت أر اضي للعشائر في العادة ومن أحسن أر اضسي الدولـة مما زاد في قبضتهم، غير المنتجة أساسـا، على الزر اعة وفي الإبقاء على قراهم ـ في الوقت نفسـهبعيدة عن سيطرة الحكومة .وقد مكنتهم الملكية من أن بثقلوا بقوة متز ايدة كاهل الفلاحين الذين تدنت

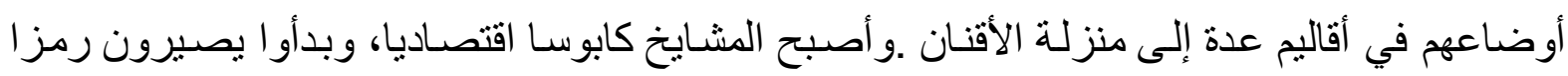


للتباين الاقتصادي الهائل الذي أخذ في هذا الوقت بعيق، وحتى أكثر من العثائرية ــ التي صسارت هي نفسها مهددة بهذا التباين - اندماج المجتمع و إدخال الفلاحين في نطاق الحياة الوطنية"( له". ويذكر بطاطو أيضا أن السلطة الملكية بتحالفها مع الثبوخ نوققت في واقع الأمر عن الدور الذي يسعى للتوحيد الاجتماعي('). وبما أنها التزمت البنية الاجتماعية الريفية حسب رأي بطاطو أيضا فقد حكمت على أكثرية سكان العر اق بـأن يعيشتو ا بأوضـاع هابطـة(' ) وشكلت في قادم الأيسام مأزقا اجتماعيا، ومانعا لتقدم الاقتصاد العر اقي في كافة مجالاته(بَ') مما حول وبتو الي الأيسام السلطة الملكيـة إلى عائق لأي تقدم اجتماعي، لا بل تحولت إلى عامل تخلف اجتماعي(ّا). ولم بكتف عبد الإله بن علي بانصـهاره بالكامـل مـع طبقة الثبوخ ومسـاندتهم في الحصـول على أكبر المقاطعـات الزر اعية، و على لـى الدخول في مجلس النو اب بل اتجه لإدخال عوائل الثيوخ في الجانب التنفيذي لكن ما أعاقه هو مستوى هؤلاء المتدني في القر اءة والكتابة. و الدليل على التصاق رموز الحقبة الملكية بالثيو خ دخول مـا يقرب

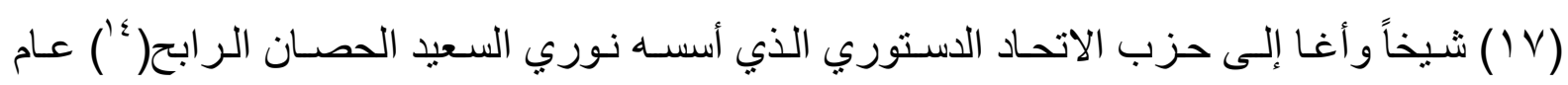
و 9 اوفي الإدارة العليا له ومن ضمنهم الأمير حمح الحبيب والثيخ عبد الله الياسين(10). ويؤكد بطاطو

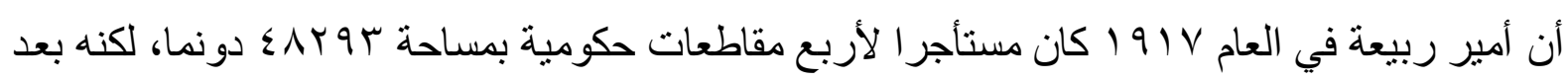

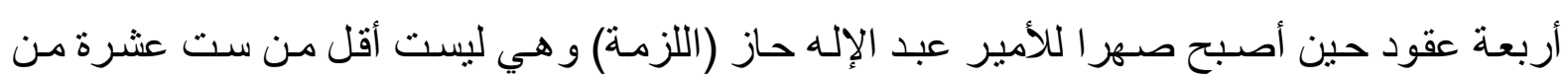

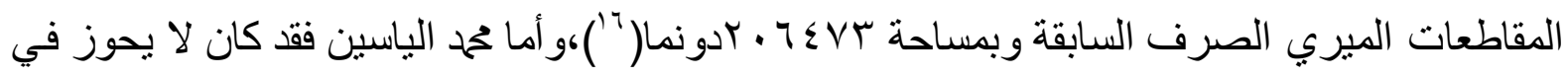
تللك السنة غير ثلاث مقاطعات ـ نصف مقاطعة بالطابو و البقية بالاستنئجار لكن عند العام 90 الحاز

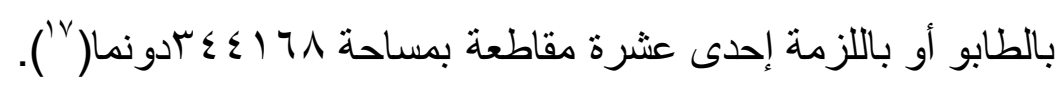

هم:رة النفلاح:

لم يبق للفلاح ما يخسره في مسقط رأسه، وفي حقله و أرضه اذ فقد كل شيء سوى الرحيل عنها

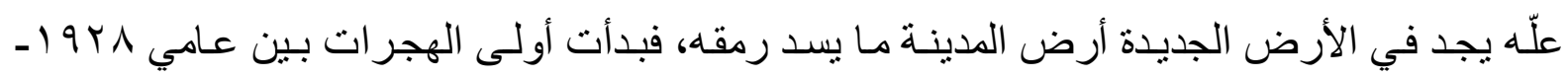
• بهو ـ ففي المنطقـة الجنوبيـة " هـاجر الالاف مـن سكان الأهوار تجذبهم مغريـات الكسب في المدن وتدفعهم قساوة الثيوخ ونردي أسعار المحاصيل الزراعية، ينشدون حياة أفضل، وبلغت حركة الهجرة

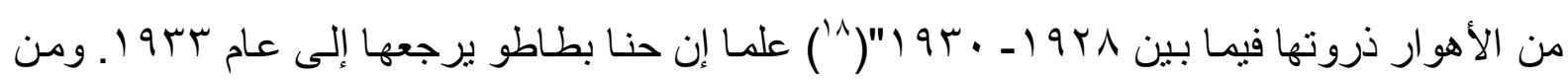
هذا الوقت بدأ ينظر إليها بوصفها مشكلة جديـة(19). بعد ذلك بسنة توققت الهجرة بسبب البطالة في المدن، وصعوبة إيجاد فرصة عمل(·) م، ولكن ابتدأت هجرة جديدة من الريف إلى المدينة أكبر و أضخم غيرت الو اقع الاجتمـاعي للمدن الكبيرة منتل بغداد والبصرة، و هنـا يجب إيضـاح أمر مهم جدا وقبـل الخوض في أرقام الهجرات فأن هؤلاء الذين خرجوا من رحم مأساة الحقول والمزارع و الثيوخ واجهوا

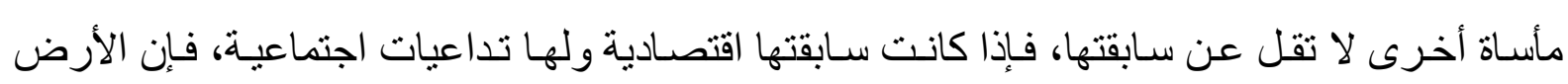


المو عودة للفلاح العر اقي (المدينة) كانـت مأسـاة اجتماعيـة في الدرجة الأولى، نظر إليهم نظرة غزاة يبغون قلع التقاليد و الأعر اف في المدينة فهوُلاء (الثر اكوة) كما أخذ أهل بغداد و غير هم يطلقون هذه التسمية عليهم تحولوا إلى (كابوس) ليس للطبقات الاجتماعية التي سكنت المدن والتي تطبعت بالطابع التركي أو المملوكي،إن لم يكن فيهم الكثير من الأصول التركية والشركسية والقفقاسية، بل تحول هؤلاء إلى مادة سياسية للطبقات الحاكمة و الأبدلوجيات و الأفكار المتصار عة معها على مسـاحة الزمن العر اقي السياسي الحديث، و لابد هنا أن نلمس حقيقة أخرى مهمة هي إن هؤلاء خر ج منهم كبار الثعر اء وأهل

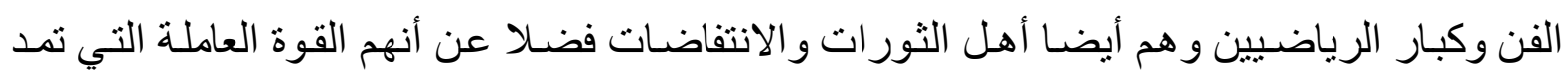

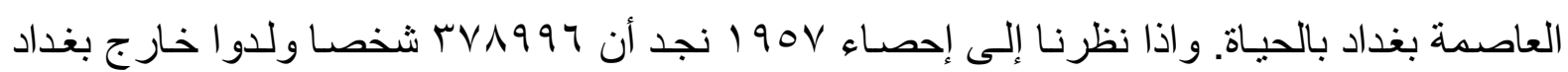

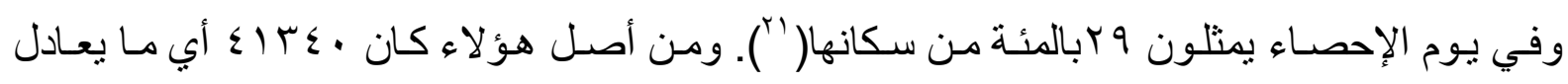

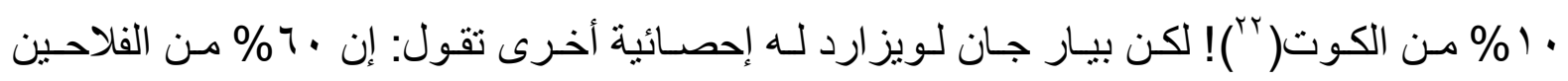
النازحين كانوا من الكوت(ّ"). و هو يعزو سبب إقامة النظام القبائلي العشـائري وتحويـل رؤسـاء القبائل إلى سادة مقابل عبيد (الفلاحين) أو كما يسميها جعلوا الثيوخ في مرتبة (ملاكك الأر اضي) يعزوه إلى هلى سعي بريطانيا لكسر التضامن القبلي الذي يعد وقتذالك قاعدة للحركات الاجتماعية و السياسية في قلب

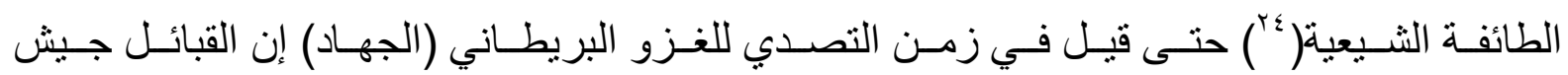
المجتهدين(') إن. وبعد الهجرة وحسب لويز ارد أضحت فتاوى المجتهدين لم تجد القاعدة الاجتماعية التي تحتاجها لمقاومة الانتداب البريطاني إذ هنالك قرى من المناطق الشرقية لدجلة والكوت و العمارة أفرغت من أهلها بسبب هذه الهجرة الريفية الواسعة التي لا نظير لها في الوطن العربي(ج).وردا على بيار جان لويز ارد في أن النسبة الأكبر من المهاجرين من الكوت لابد من ذكر إن طبيعة مدينة مثل الثورة (الصدر) تطبعت بطابع العمارة وتحولت فيما بعد إلى عمارة كبيرة وليس صغيرة. و هكذا الحسال في منطقة الثعلة في منطقة الكر خ من بغداد مما يشير إلى أن من هاجر من العمارة أكثر ممن هاجر من بطن الكوت.

\section{تأخر الزراعة}

لحامد مصطفى المقصود ر أي في أسباب الهجرة الفلاحيـة من الريف إلى المدينة (العاصمة تحديدا) فهو يعزو هـا ليس فقط إلى الظلم الاجتمـاعي و الاقتصـادي حين يورد عنهما صورة قاتمـة( (r) ففضلا عن كل الأسباب التي أوردناهـا يذكر حامد المقصود أسبابا أخرى هي: تخلف العمل الزر اعي وجهل الفلاح وقلة درايته وخبرته عامـة(^^) و أيضـا ركود الحالة الاقتصـادية في العر اق لاسبما ركود الاستثمار في الريف العر اقي. كل هذه أسباب جعلت من فرص العمل في الريف تصل إلى أدنى مستوى 


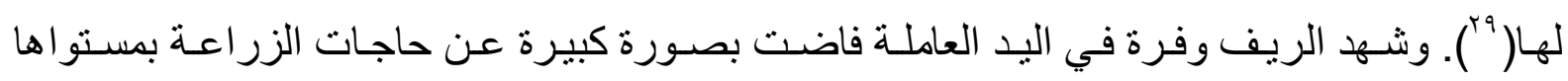

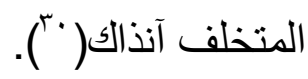

\section{الصرائف هرة أخرى:}

في الصر ائف رقم كبير من أهل الكوت انتقل إلى هذه الصر ائف التي غلفت بغداد في أكثر

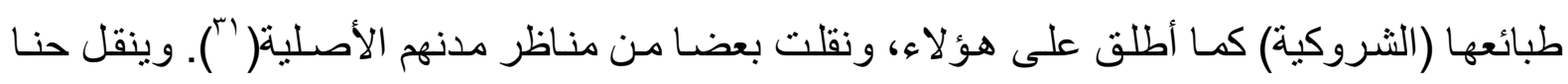
بطاطو في إحصائية دقيقة أرقامـا من المكتب الرئيس للإحصاء تفيد بوجود با اء 1 ا صريفة في عام

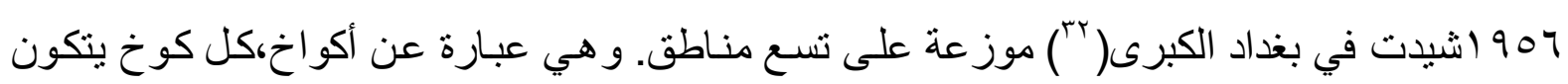

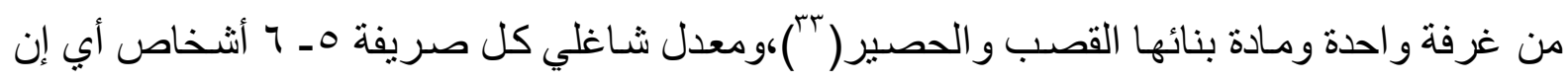

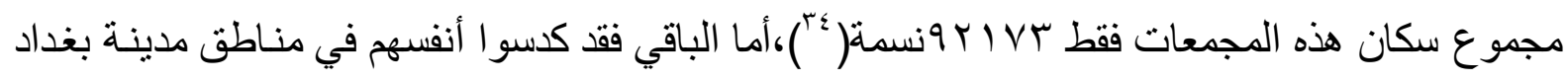

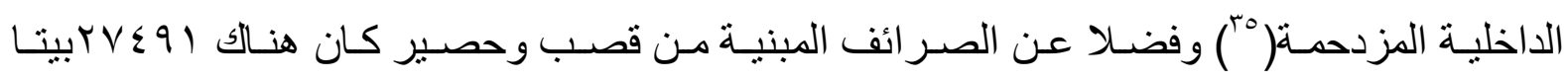
طينيا(كو خ) في بغداد الكبرى("َr) سكن فيها المهاجرون من العمارة و الكوت.

عاش المهاجرون، سكان الصر ائف حياة صعبة للغاية ففي عام 90 1 قام الدكتور (كريتشلي) من كلية الطب في بغداد بمسح على مجموعة من هذه الأكو اخ فوجد أن هذه الأكواخ بنيت في موقع

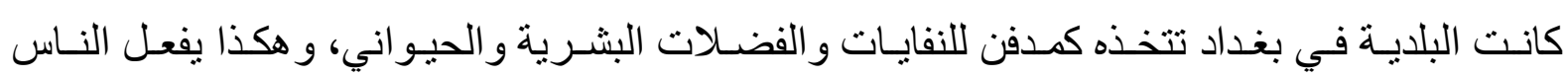
الاعتياديون( (v). هذا، "وكانت بعض مياه مصارف سطح أرض المدينة تضخ أيضا إلى المنطقة بحيث.

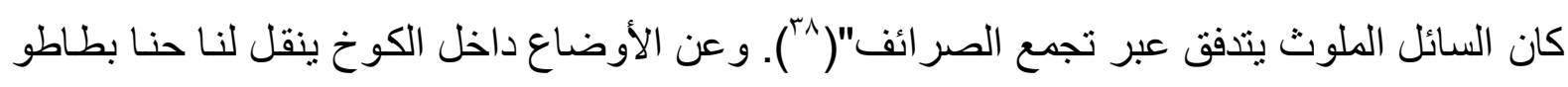
عن الدكتور كريتشلي ما نصه إن " الأكواخ سيئة التهوية، مزدحمة،ليس فيها ما هو خاص، وكثير ا ما كانت تأوي الحيوانات المنزلية إلى جانب العائلة. ولم تكن في الصر ائف أو في المنطقة أية ترتيبات صـية (بمعنى المجـاري و المر احيض)..وكـان السكان بتغوطون - ببسـاطة ـ أينمـا كان ...ولم يكن هنالك أي تزويد بمياه نقية للثرب. وكان يجب نقل هذه المباه من خارج المنطقة وتخزينها في (حب) وكان الأثاث المعتاد عبارة عن صندوق فج وبعض أدو ات الطبخ وفر اش واحد تكوم فوقه بطانيات نوم بقية أفر اد العائلة الذين كانو اينامون على الأرض، ويعتقد إن كل لقمة طعام يتناولها هؤلاء الناس كانت ملوثة. ووجد أن معدل وفيات الأطفال اء世 لكل . . . احالة حمل. ومن الو اضح أن أوضـاعا معيشية كهذه لم تكن مؤذية بالنسبة لصحة سكان الصر ائف فحسب، بل كانت تهدد سكان بغداد أيضا"( ("). ونستمر في توضيح حالة المهاجرين من الكوت و العمارة إلى بغداد نتيجة استشر اء الإقطساع وشعور الفلاح بأن الحيـاة قد انعدمت هنـا ولابد من الرحيـل مهما كلف الثمن من متاعب وصـعوبات لاسيما إنهم يتلقون أخبار ا بأن سابقيهم قد انخرطوا في أعمال و إن لا تقل مهانة عن حياتهم السابقة لكنهم بستطيعون الخـلاص منها وقت شـاءو ا، ويسمعون أيضـا إن العديد منهم قد انخرط في سـلك الثـرطة 
و الجيش مما شكل حافز ا للباقين في أن يهاجروا، فظلت هذه العملية بلا انقطاع حتى بعد ع / اتموز /901 الاسيما بعد البدء بتسجيل الأسماء التي ستوزع عليها المسـاكن في الثورة و الثعلة و الرحمانية. لكن هؤلاء المعدمين و المسـحوقين القادمين مـن العمارة والكوت( •؛) و الذين سكنو ا في الميزرة (أي المجزرة) في منطقة شيدت عليها فيما بعد منطقة النهضـة ومنطقة النـاكرية (نسبة إلى شـاكر الو ادي وزير الدفاع في العهد الملكي) وهي الآن كر ادة مريم و إن ظلاو ايعـانون اقتصـاديا واجتماعيـا نتيجـة حسابات سياسية واجتماعيـة رافقت بناء المجتمع السياسـي العر اقي إلا أنهم تحولوا إلى عصب الحياة العر اقيـة كلهـا و المجتمـع البغدادي على وجـه الدقة وفي كل مجالاتهـا كمـا أسـلفنا، وليس فقط طو عتهم الحكومة الملكية في سلك الثرطة لقمع المتظاهرين و المعارضين لحكمها كمـا يصور البعض وتصور الحكومات ومنهم حنا بطاطو الذي يذكر "كانت شرطة بغداد قد (تعرنت) (نسبة إلى المهاجرين من العمارة) إلى درجة غير بسيطة، مما أعطى سمة خاصـة لما أصبح في المرحلة الأخيرة من مر احل النظام الملكي أداة قمع كلاسيكية .ولم يكن هنالك أبدا مقدار و افر من التعاطف بين أبناء العثـائر وأبناء المدن، وذلك يعود بدرجة كبيرة إلى قلة الاتصال أو التماس الحقيقي بين الجماعتين"( () لكن هل يكفي هذا ليتطوع هؤلاء في الثرطة القمعية لو لم تسد طرق المعيشـة الأخرى أمامهم، وهل تقتصر صورة ابن المدينة الر اسخة عند المهاجر من الكوت و العمارة فقط على المرابي و الجشـع(r) فكيف إذن اقتنعوا بعد حين بطروحات أبدلوجية انضموا إليها وتعرضوا إلى شتى صنوف التعذيب و القتل لتكون اضـافة للقهر الاجتماعي الذي مارسته الحكومات المتعاقبة والمجتمع على حد سواء، ونعلم أن الأيدلوجيات جاء بها أبنـاء المدن المـر ابين و الجثَعين وليس أبنـاء الريف.وبنـاء على هذه النظرة كانـت حسالات القتـل و الجر ائم الكبرى تتجـه أنظـار السلطات فيهـا إلى هذه الرقعة ذات الكثافـة السكانية العاليـة، و المســن المتلاصقة ببعضها و المنتابهة البناء نتيجة للتغذية الذهنية الرسمية ضد هذه الثريحة.

النظرة العدائية لهم: يذكر عبد الكريم الأزري إنه في أواخر سنة 900 أو أوائل 1900 أنه طلب من نوري السعيد رئيس الوزراء حينها أن يشاهد بأم عينيه وضع المهاجرين من جنوبي العر اق الذين كانوا حسب وصفه يتكدسون فيما كان يعرف وقتها بـ(العاصمة)(" "). ويصف الأزري الحال بما نصـه "هنالك كانت تتكدس هذه المجموعـة البائسـة مـن المهاجرين مـن جنـوب العر اق بأعداد هائلـة وقد سـاقتهم ظروفهم و الظلم الاجتمـاعي الذي كـانو ا يقاسـونه في مـواطنهم الريفيـة و إهــال الحكومـات لهم إلى الهجرة إلى بغداد و الإقامة فوق هذه المياه الآسنة القذرة السوداء مـع حيو انـاتهم. وكان منظر هم، وخاصـة أطفالهم العر اة يتخبطون في الأوحال ويتعرضون للغرق في تلك المباه القذرة، وهو مـا يفتت الأكباد ويدمي القلوب

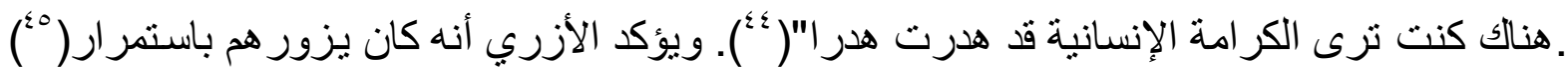


و هو الذي شـل منصب مسؤول البلاط الملكي مدة مـن الزمن ووزير للمالية ونـاب برلمـاني أيضـا،

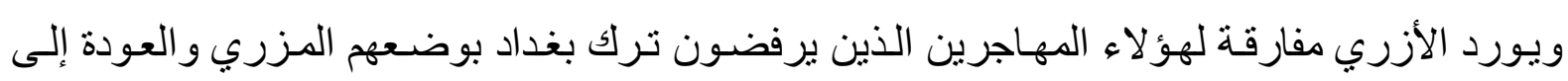

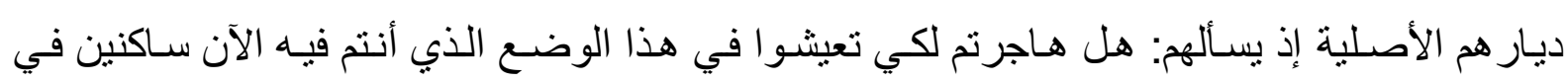
((صر ائفكم) المنتشرة وسط هذه المستنقعات وهذه المياه الآسنة القذرة؟ فيجيبوه: إن وضعنا هذا الذي الذي تر اه، على سوئه، أفضل بكثير من وضعنا الذي كنا فيـه هناك إننا نجد هنا، على الأقل، مجالا للعمل مهما كان وضيعا - نؤمن بـه رغيف العيش فلا نموت جو عا ونكسي بـه أنفسنا فلا نمشي عر اة ـهل تتصور أنتا نترك (ديرتتا) و(وطننا) لولا الضيق الذي كنا نعاني منه أشد المعاناة و الذي كان يخنق أنفاسنا"( ") وبعد أن يورد كيف استجاب نوري السعيد لر غبته في زيارة منطقة الصر ائف و أمره ببعض المعالجات البسيطة يذكر الأزري إن السعيد دفع لله متصرف بغداد عبد الجبار فهمي فيصفه إنه تقرير

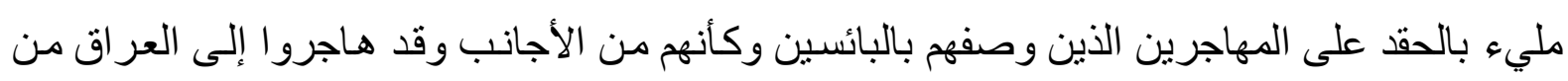
بلد آخر( (₹)! ثم يسترسل فيذكر "وقد صبت اللجنة جام غضبها عليهم لا لذنب اقترفوه سوى إنهم جاؤوا بأعداد كبيرة إلى بغداد، فغيروا وضـعها الديمغر افي، و أخذوا يضـايقون، حسب رأي اللجنـة، سكانها

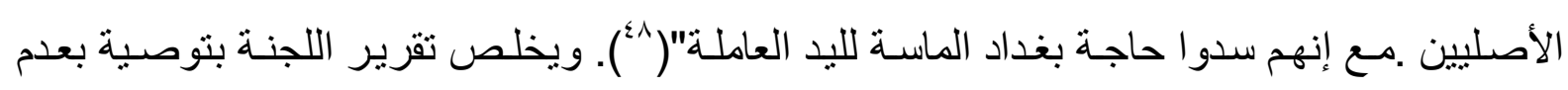
تسهيل أمر المهاجرين بالبقاء في بغداد بمنحهم أر اض سكنية أو بناء دور لهم( ؛وء). إن العقلية التي أنتجت هذا التقرير تعاني تر اكمات عثمانية قديمة وتعاني من خشية وخوف على وجودها، و على مر اكز ها، وفعلا تحول هؤلاء إلى الرقم الأول في الحر الك السياسي و الاقتصسادي

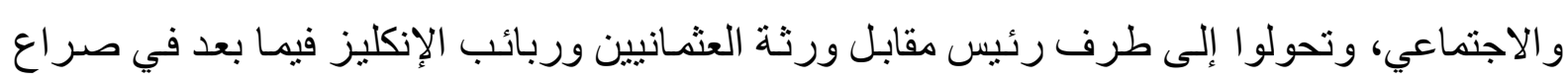
وجودي اتخذ عدة وجوه، تارة يسارية، وتارة أخرى دينية وأخرى طائفية و غير ذلك من الوجوه.

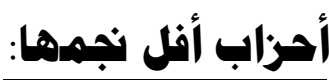

في خمسينيات القرن العشرين بزغت أحز اب جديدة لها طروحاتها الجذابة للشباب أكثر من أحز اب سيطرت بخطاباتها الوطنية والقومية لا بل استقطبت الكثير من شباب تلك الأحزاب، و هذا الأمر شـل حزب الاسـتقلال أكثر مـن غيره والحزب الـوطني الديمقر اطي لحسـاب حزب البعـث وحركة القوميين العرب وأحز اب أخرى، لتبى الساحة فيما بعد أي في نهاية الخمسينيات و عقد الستينيات للبعث

$$
\text { و الحزب الثيوعي العر اقي . }
$$

حزب الاستقلال: حزب قومي بامتياز تأسس من خـلال أعضـاء نـادي المثنى الذي كان بمثنل الاتجـاه القومي منذ ثناثينيات القرن العشرين. وجاءت الفكرة في المعتقل إثر فثنل حركة اءئ 19 و هنالك رأي

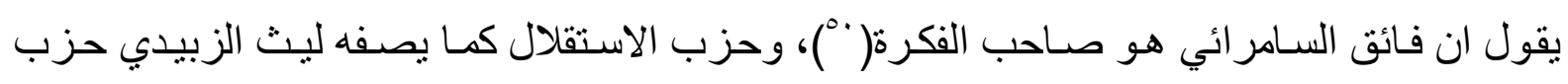
برجوازي اقتصـرت قيادته و أعضـاؤه على الطبقة البرجوازيـة والمثقفـة ولهذا السبب كان عملـه غير 


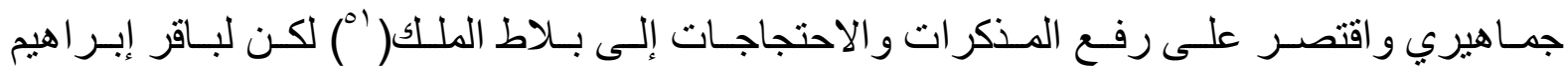

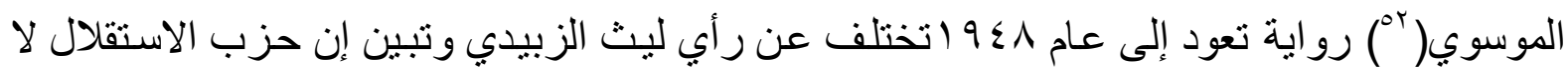
يختلف عن باقي الأحز اب في ضمه لعناصر تؤمن بالعنف طريقا في تصفية حسـاباتها مـع الأحزاب المنافسة الأخرى على الساحة العر اقية، فبعد العمل الكبير الذي اضطلع بـه طلاب (كلية الملك فيصل) و"منذ الأيام الأولى لثهر كانون الثاني، كان طلبة كليتنا يشاركون مع طلبة وجماهير الأعظمية، وبغداد كلهـا، مشـاركة نشـيطة في التظـاهر ات، احتجاجـا على المباشـرة بعقد المعاهدة الجـائرة بـين العـراق وبريطانيا (معاهدة بورتسموث)"( بَ). وبعد أن يسرد كيفيـة التظـاهر ات والانتصـار فيها يذهب بـاقر إبر اهيم الى أن هذا جعل الدو ائر الأمنية تتربص بالقوى الوطنية الدوائر وحياكة الدسائس بينها، يساعدها في الثـعار ات المرفوعـة المتعارضـة التي رفعتهـا الأحز اب الوطنيـة (ْ) إثر ذلك حدثت اسـتفزاز ات ومشاجر ات و عر الك بالأيدي بين الثيو عبين والقومبين الذين كانوا قلة فانسحبو اليعقب هذا الانسحاب اللافت للنظر مداهمة للكليـة من قبل الاستفز ازيين( (1). لجأ الطلبـة الذين حوصرو ا في الكلية إلى سد الأبو اب و المنافذ في الكلية وأحاط الطلاب أسر هم بالأمر و اتصلت الإدارة بالجهات المختصة فلم يحرك ساكنا وبدأ الهجوم في يوم تثبيع شهداء الوثبة بعد وصول حشود كبيرة في الليلة السابقة وكان هجوما عنيفا استخدمت فيـه الهر اوات و المدي و القضبان وقبضـات الحديد وكانـت ضـرباتهم توحي بـأنهم قد تـدربو ا على مثنل هـذه الأعدـال("). هـذا، وقـد أصـدرت الأحـز اب الثنلاتـة: الاسـتقلال، و الـوطني الديمقر اطي، و الأحر ار بيانا يصفه باقر إبر اهيم بالعمومي، علما إن الاستقلال قد وجهت بعض الإدانات

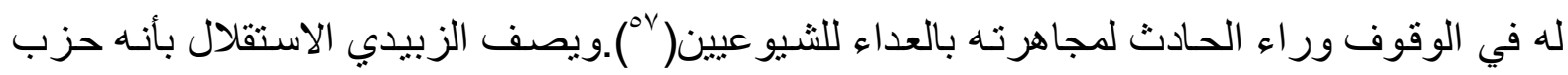
قومي لكنه إقليمسي في تنظيماتـه ولم تتعد حدود العراق(^ه) إذ كان بنـادي ويدعو للوحدة العربية لكن بشكل عاطفي(1). اثتنرك هذا الحزب في إقامـة جبهة الاتحاد الوطني مـع الحزب الثـيوعي العر اقي وحزب البعث و الوطني الديمقر اطي التي سـنتناولها بالبحث لاحقـا. وهنـا يجب أن نلاحظ أن حزب الاستقلال و على لسان زعيمه أقر وكما مبين في الهامش أدناه بقصد أو دون قصد باستخدام العنف في العمل السياسي. ولا غرو إذ نجد القوميين العرب و البعثيين قد استمر أوا العنف من أيام حزب الاستقلال فانتمو إلى جهات تؤمن بالعنف أصلا طريقا في حياتها السياسية لاسيما البعث ومثله حركة القوميين العرب.

الحزب الوطني الديمقر اطي: ارتبط هذا الحزب باسم مؤسسه أو رئيسه (كامل الجادرجي) وهو إرث جماعة الأهالي التي كان لها أثر مهم في انقلاب بكر صدقي عام بسو ا ـ وكانت جريدة الأهالي النواة الأولى لتأسيسـه إذ صدرت مجددا عام بـ 9 ا ـ ولم يمـارس الحزب نشـاطه العلني إلا بعد أن أجيزت

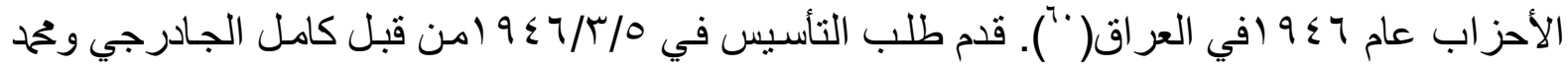


حديد و عبد الكريم الأزري وحسين جميل وقد تمت الموافقة عليه في //عدن العام نفسـا("). ويضيف ليث الزبيدي: إن الهيئة المؤسسة ضدت فضلا عن الأسماء المذكورة شخصيات برجوازيـة أخرى مثنل عبد الوهاب مرجان و عبود الثالجي، ولذلك وصف الحزب بأنه بمثل الحركة الديمقر اطية المعتدلة( بآ). إن كلا من كامل الجادرجي وخحم حديد وحسين جميل وصادق كمونة كانو ا قد انشقو ا عن جماعة الأهالي وكونو الحزب الوطني الديمقر اطي مـع بعض الديمقر اطيين المحافظين، الأمر الذي حدا بعبد الفتاح

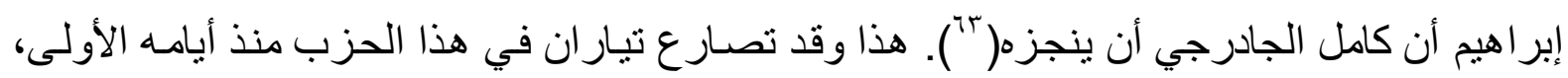
الأول يمثله فاضل حسين الذي لم ينضم للحزب كونه مدرسا (موظفا) لكنه استطاع أن يتفق مسع كل من طلعت الثيباني ابن مدينته وزكي عبد الوهاب وأقنع أصدقاءه القدماء من الطلبة السـابقين الذين تأثروا بآر ائه وتوجيهاته في الانضمام للحزب فكونو ا جناحا يساريا يقاوم الاتجاهـات المحافظة للجناح اليميني

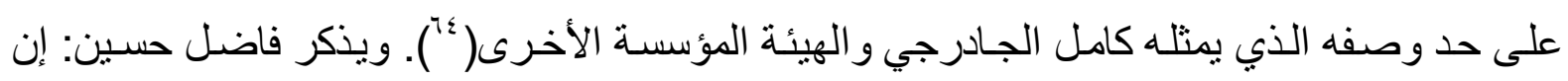
العادة جرت في الحزب و على مدى حياة الحزب في أن بنتخب كامـل الجادرجي ومححد حديد وحسين جميل لعضوية هيئة الرئاسة في الحزب المذكور مما حفزه بتوجيه رسالة إلى اللجنة الإداريـة ينتقد فيها الاتجاهات الجديدة في الحزب و التنظيم السيئ والسلطات الو اسعة التي تتمتع فيها هيئة الرئاسـة واصفا الحزب بأنه لا ديمقر اطي ولا وطني الأمر الذي أغضب أعضاء اللجنة بثدة( (ب).و يصف فاضل حسين الحزب بأنه قام على ركائز ثلاث هي زعامة الحزب و انحصرت بكامل الجادرجي ومحمد حديد الذي منل الخبير و المثقف بالأمور الاقتصسادية، وحسين جميل ويصفه بلولب الحزب ومحركه وخبيره القانوني و الدبلوماسي(" ) .و الركيزة الثانية جريدة الأهالي و أخو اتها على حد تعبيره، و الثالثة قو اعد الحزب التي لم يكن اثر ها محسوسا بشكل كبير فالحزب يعد حزب المتقفين ومن الأحز اب الضعيفة فلم يستطع القيام بأي عمل منفرد إيجابي مهم مثل تنظيم مظاهرة أو إسقاطوزارة ويصفه بأنه دائما كان عالة على غيره

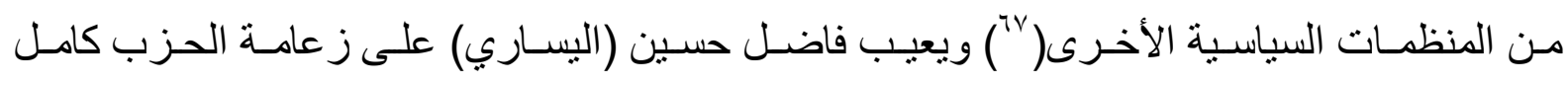
الجادرجي (اليميني) بأنها عاجزة عن منع تسلل بعض الثـيو عيين إلى الحزب بقصد السيطرة عليه

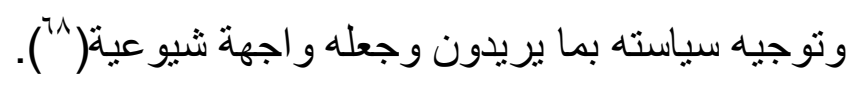

وقد يسأل سائل إن الوطني و الاستقلال ساهما في جبهة الاتحاد الوطني مـع البعث و الثبيوعي وقد أضعفا الحكم الملكي ومن ثم الإطاحة به ؟و الإجابة على هذا السؤال تكون من عدة وجوه، الأول إن الحكم الملكي قد وصـل مداه في ذلك الوقت و لابد أن يزول بفعل العو امل التي ذكرت أعلاه وبفعل شيخوخة القائمين عليه و عدم السماح بتصدي وجوه جديدة و أيضا وصل الحال في ذلك الوقت الى حد أن أي فصيل أو حزب وكيان إذا تحرك قبل غيره سيتمكن من إسقاط هذا الحكم لكن هذا لا يعني إلغاء أثر الحزبين في تللك المدة ولا ينكر إن قيادة الحركة في ع / / تموز قد اتصلت بكامل الجادرجي في سجنه 
ومن ثم عينت محمد مهدي كبة زعيم الاستقلال عضو ا في مجلس السيادة لكن أثر هما ليس كأثر الثيو عيين

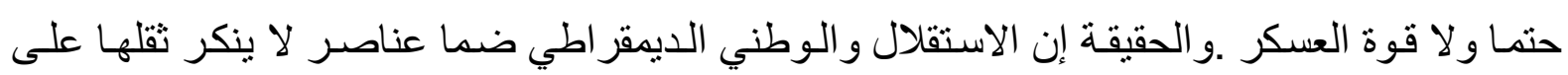
النخبة ولا حتى تأثنر ها في مجريات الأمور .

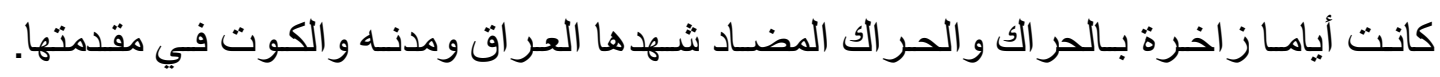
الحركات الوطنية متفاعلة مـ الأحداث سو اء كانت في العراق أم في الوطن العربي، أحزاب تآلفت وتحالفت، تصار عت وتنافست بحدة، كونت جبهة ضد الحكم القائم، تظاهرت سوية، احتقلت بسقوطه أيضا سوية، جابهت السلطة وإن بتفاوت الأعداد لكن تواجد أي فرد من أي حزب يحسب له ولحزبه. تأسست في هذه الحقبة أيدلوجيات مقابل أيدلوجيات، لم يكن العراق غائبا في هذه الحقبة عمّا

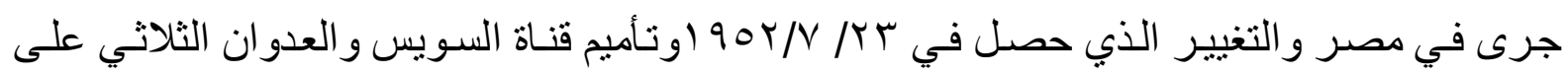
مصر بقيادة بريطانيا، وفرنسا، و إسر ائيل. فتفاعلت الجماهير تفاعلا شديدا حتى أعلنت انتفاضات متعددة في العر اق وليس انتفاضـة و احدة تتدد بهذا العدوان، وبموقف السلطة، وكانت للكوت حصـة وحصـة كبيـرة تمثلــت في مظـاهر ات خرجـت في الكـوت (المركـز) و الفيصـلية (العـزة حاليـا) وفي مدينـة النعمانية(997) وكانت الحصة الأكبر في انتفاضـة الحي و إعدام علي الثيخ حمود وعطا الدباس نتيجة اشتنر اكهما في تلك الانتفاضة.

ونؤكد كما في كل مرة إن النظام البوليسي القاسي، و عمليات البطش، و التعذيب، و التصفيات إنما أسست في الحقبة الملكية وكان مصداقها ما حدث في 907 اسو اء في الكوت أو في غير أمسكن من العر اق مثنل النجف وبغداد و العمارة والبصـرة لكن تبقى حادثة الحي هي الأبرز. وفي الخمسينيات وبالتحديد في 90 اوبعد أن استشرى الإقطاع في العراق، وفي الكوت أيضـا حيث حدثت الهجرات الداخلية الكبرى من مدن أو معاقل الإقطاع نحو البصرة وبغداد العاصمة التي أخذت العدد الأكبر من المهاجرين الفلاحين و عندما نلقي نظرة على إحصاء 90 ا نجد إن الذين كانو ا يعيشون في بغداد لكنهم

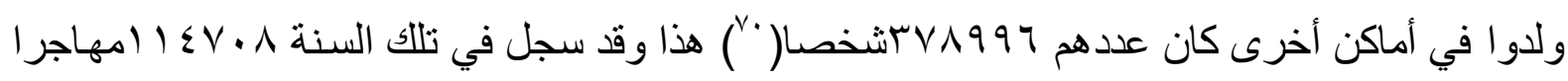
من العمارة و . ع آع مهاجر ا من الكوت("). لكن هل كانت انتفاضة الحي وقبلها أحداث سجن الكوت و الهجرة هي فقط ما خزنته ذاكرة أهل الكوت من أحداث؟ سنجد في شهادات أبناء الكوت ومـا حوته ونه الوثائق الأمنية بأن في هذه المدينة وفي هذه الحقبة تحديدا حر اكا سياسيا هائلا طالما أكدناه. 


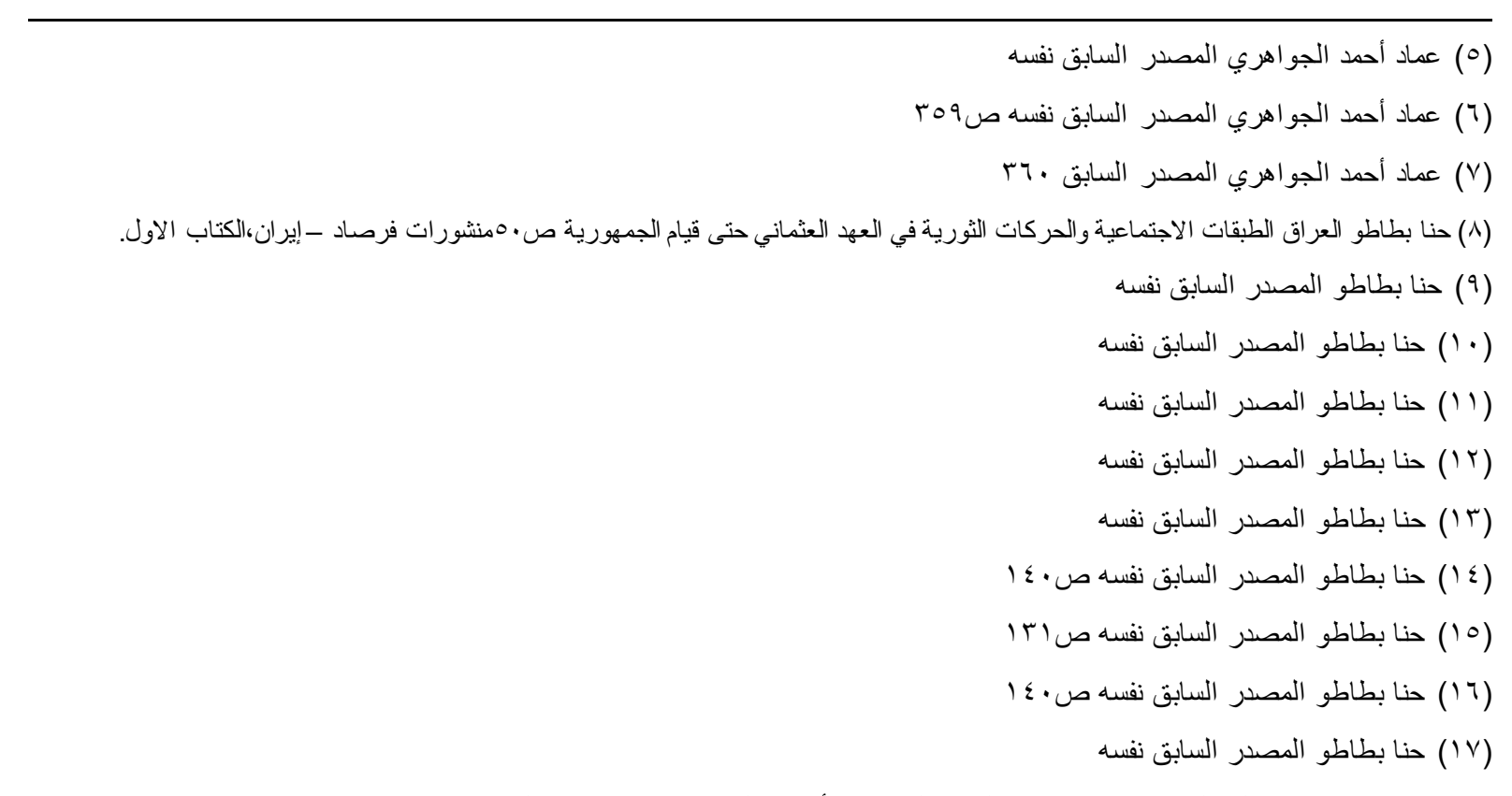

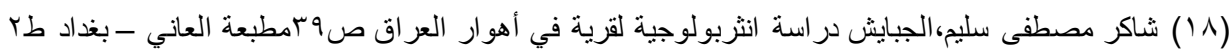

(19)

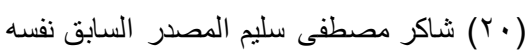

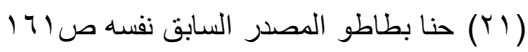

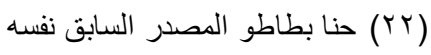

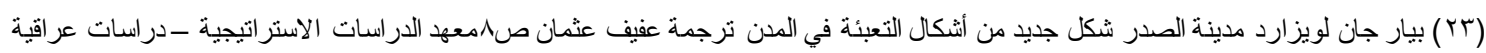

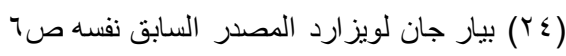

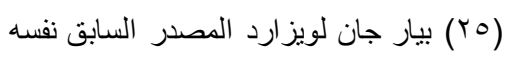

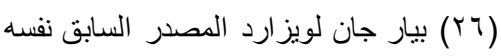

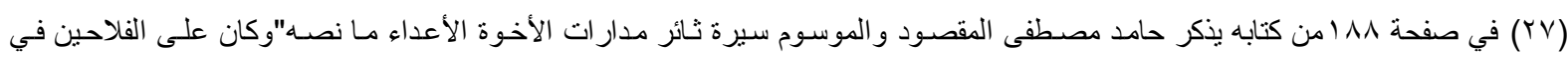
العمارة(تذكر العمارة كباقي الألويـة) أن يزر عو ا قطعة الارض المخصصـة لرجـال الدين المو الين للاقطـاعيين و التي تعرف (المحرمات)،وكان

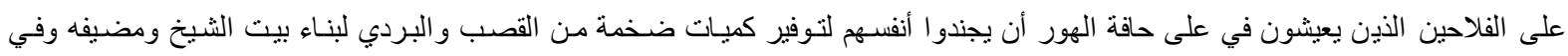

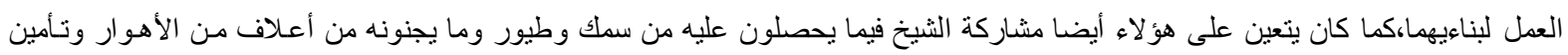

الحطب له وما يجمعون من ريش الطيور لحشو الوسائد وتجمع النسوة لتهبيش الرز لله".

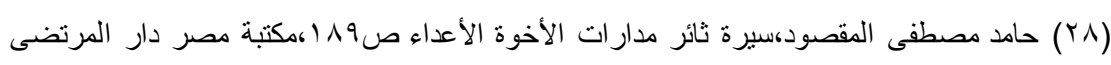

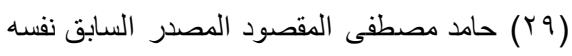

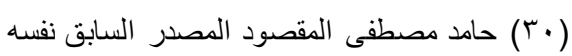

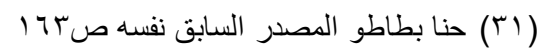
(rrr) حنا بطاطو المصدر السابق نفسه (Tr) حنا بطاطو المصدر السابق نفسه ( (ץ) حنا بطاطو المصدر السابق نفسه (ro)

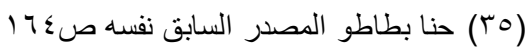
(T־ץ) حنا بطاطو المصدر السابق نفسه (rV) حنا بطاطو المصدر السابق نفسه (r^) حنا بطاطو المصدر السابق نفسه (rv) 


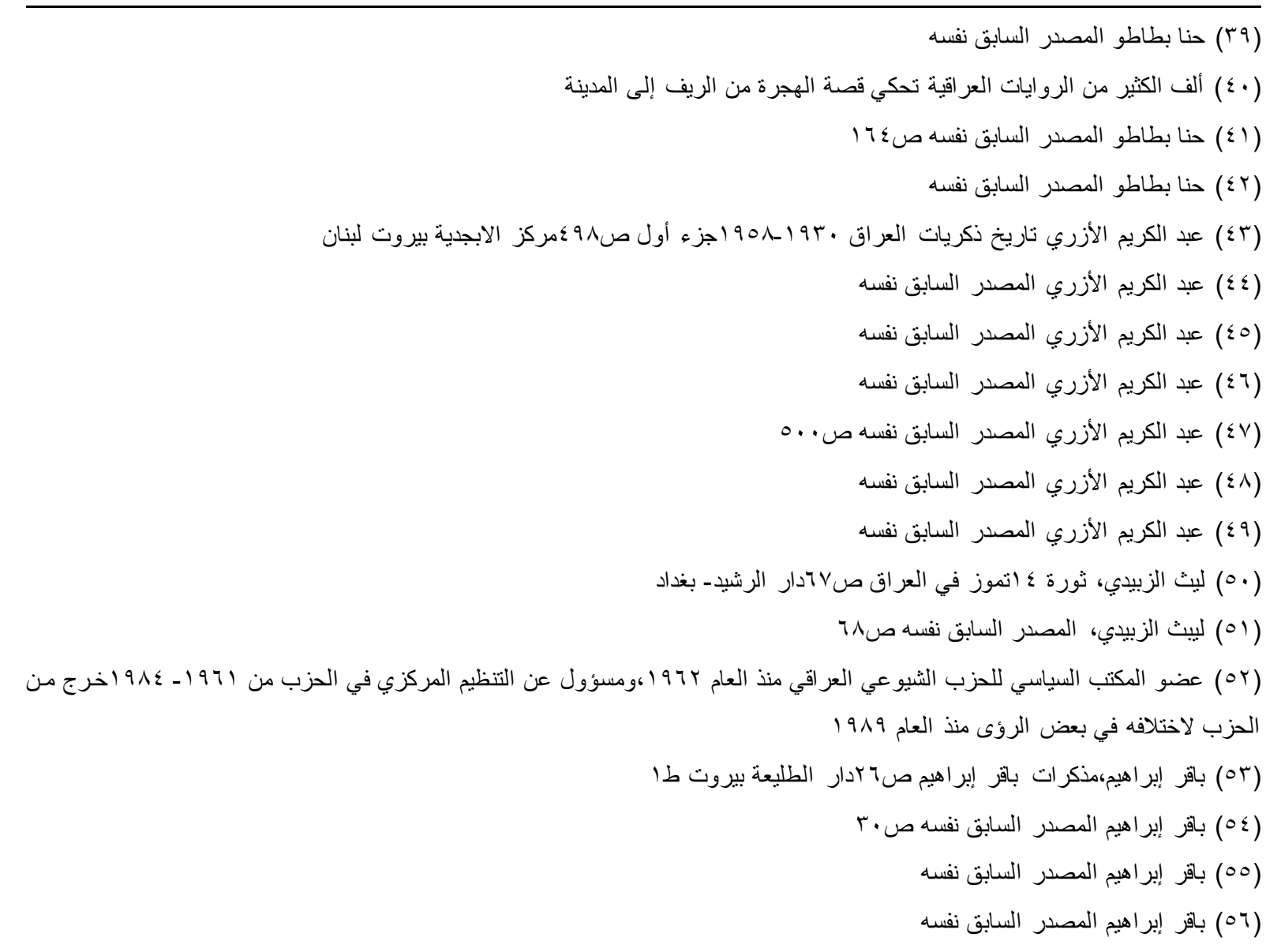

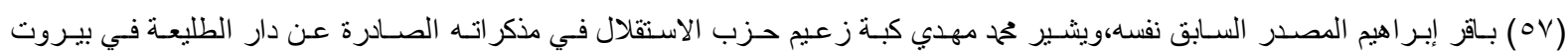

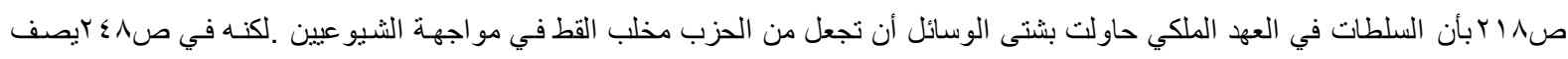
الحال الذي ذكره باقر إبر اهيم تحت شغب الثيو عيين و انهم استمروا في شغبهم وتظاهر اتهم ويطوفون في الثوارع ويتجمعون في السـاحات العامـة

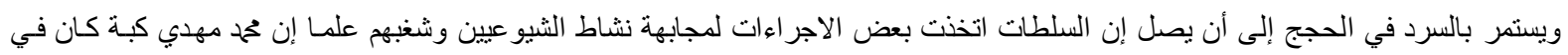
ذلك الوقت وزير ا للتموين في الحكومة. (ON) ليث الزبيدي المصدر السابق نفسه (1) ليث الزبيدي المصدر السابق نفسه

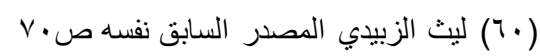
(1) (بآ) ليث الزبيدي المصدر السابق نفسه

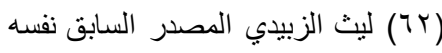

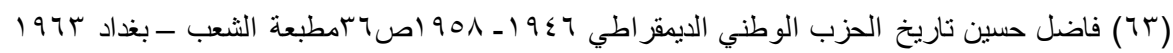

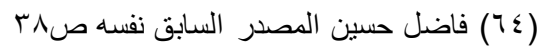

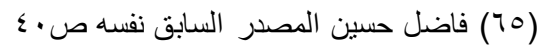

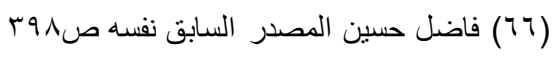
(TV) فاضل حسين المصدر السابق نفسه

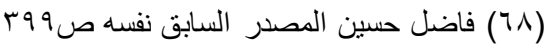
(797) أحرار العراق،انتفاضة العراق الأخيرة عرض وتحليل صوهـ بلا مؤلف ولا دار نشر

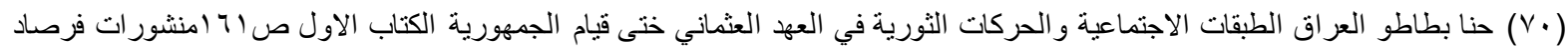
(V) حنا بطاطو المصدر السابق نفسه 